\title{
Synergetic Approach in Shaping the Content of Teaching Stochastic to Economics Students
}

\author{
Natalia Shulga* \\ Department of Mathematics and methods of teaching mathematics, Cherkasy National University named after B. Khmelnitsky, \\ Cherkassy, Ukraine \\ *Corresponding author: schulganv@i.ua
}

Received September 22, 2014; Revised October 27, 2014; Accepted December 14, 2014

\begin{abstract}
This paper demonstrates the possibility of using non-linear approach to formation of the study content of Stochastics to the students of economic specialties of the universities. The author suggests a synergistic model of content based on the interaction of three elements: 1) the trajectory as a succession of content units and topics; 2) connections that can create synergies content; 3) content, which is represented as a combination of basic concepts and methods of stochastic analysis of random phenomena. The document also reveals the possibility of practical application of the proposed model.
\end{abstract}

Keywords: synergetics, Nonlinear Dynamics, complexity, self-organization, Synergetic Educational Model, Stochastic Training of Economists, the Content of Teaching Stochastics

Cite This Article: Natalia Shulga, "Synergetic Approach in Shaping the Content of Teaching Stochastic to Economics Students.” American Journal of Educational Research, vol. 2, no. 12B (2014): 46-50. doi: 10.12691/education-2-12B-9.

\section{Introduction}

Current economic activity is influenced by a large number of external and internal random factors that cause stochasticity, nonlinearity, unpredictable, risky social and economic processes [2,3]. These processes are characterized by complexity, dynamics, increasing interaction between different kinds of elements (which, in turn, are influenced by qualitative and quantitative changes), regardless of the subjective behavior of the process, the level of scientific and technological process, changes in consumer demand, the impact of climatic and socio-cultural changes [11].

Sources of random effects are the random nature of possible outcomes, availability of alternatives, uncertainty, in which economic processes occur and of loss or additional income. As a result, it is necessary to analyze the impact of possible uncertainties in economic performance and assess its risks. An effective instrument of this analysis is stochastic as a mathematical discipline that aims to research situations or patterns that characterized accident, multiplicity, uncertainty.

Competence in the use of stochastic methods in the profession is one of the important characteristics of an economist. In addition, the stochastic training is the basis for the study of many economic disciplines, such as econometrics, insurance, economic analysis and more. Therefore, in most educational institutions that train future specialists economic sector, Stochastics is one of the basic courses.

Analysis of curriculum of disciplines aimed at the formation of knowledge and skills with stochastics showed that there are two basic approaches to the structuring of linear stochastic training content: differentiated $(\mathrm{P} \rightarrow \mathrm{S})$ and integrative $(\mathrm{S} \rightarrow \mathrm{P} \rightarrow \mathrm{S})$. The essence of a differentiated approach is that the first deals with basic concepts and theorems of probability theory $(\mathrm{P})$ : random events, random variables, sometimes random process, then the notions of Statistics (S): descriptive statistics, theory assessments, tests of hypotheses, regression, sometimes dynamic series analysis and analysis of variance. Integrative approach involves the study of the first topics of statistics (S) concerning the selection, presentation and research of statistical data, the next step introduces the basics of probability theory (P) and study the theories of statistics (S) related to estimation of parameters, verification statistical hypotheses, regression, analysis of variance and analysis dynamic series.

In our view, both linear approaches have one significant drawback is that the basic concept of stochastics (random event $\leftrightarrow$ result of the experiment, the probability $\leftrightarrow$ relative frequency, random variable $\leftrightarrow$ sampling, distribution of a random variable $\leftrightarrow$ statistical distribution of the sample, etc.) are given separately, which reduces understanding of educational material, infringes logic perception of stochastic phenomena, complicates the search for methods of analysis. Susanne Prediger indicates on the problem of the gap between the perception of everyday random situations and mathematical concepts used for their study too [7]. The author emphasizes the need to revitalize the concept of probability as a strategic instrument for decision making in practical situations involving random factors. Carmen Batanero and Carmen Diaz [1] emphasize the difficulty in materializing of 
probabilistic concepts during simulation or experiments with random results. Scientists argue that such complexity can be overcome through the use the complementary nature of classical and frequentist approaches to probability.

Therefore, there is a need to find non-linear approaches related to formation of the content of stochastic training of the future economists. New approaches should reflect the interaction of the basic concepts of Probability and Statistics and their complementary nature and, due to that, contribute to complex understanding of educational material.

\section{Basic Principles of Synergetics}

Today one of the main methods knowledge of reality is Postnonclassical method of scientific rationality that considers the development of processes and phenomena as nonlinear evolution of complex systems. Direction of evolution depends on the coherent action of all elements of the system and can be changed (under certain conditions), even with negligible impact on the system (both internal and external) [12]. Among of approaches that are based on Postnonclassical method of scientific knowledge, a multitudinous methodological instruments of research of complex of open nonlinear systems capable of self-organization, has Synergetics [8]. The term "Synergetics" put into scientific apparatus by H. Haken [13], who described it as the science that studies the general actions cooperation of a large number of similar elements of open complex systems that ensure the transition of the whole system from disorder to order. In current research $[4,5,6]$ together with the term Synergetics is used as the name Nonlinear Dynamics, Chaos Theory.

Principles of synergetic systems were proposed by Vladimir Arshinov [9] and Vladimir Budanov [10]. The authors identified two groups of principles: the first group - the principles of Genesis describes the behavior of dissipative structures in phase Order; the second group the principles of Formation, describing the behavior of the system in phase Chaos. Consider these principles in more detail.

Phase Order. The first principle of Genesis system - is its ability to homeostasis. Homeostasis - a coherent system of action elements aimed at maintaining the system within certain limits, guiding the system to its aims or development program, called the Attractor. Thus the Attractor system receives signals to adjust the process of development and not allowed to deviate from the set course. The adjustment system is due to negative backward linkages submitted from the output of the system at its entrance.

The second principle: Genesis is a hierarchical system. Dissipative structures can be divided into three levels: Micro-, Macro- and Mega-levels. Elements of Micro-level in the construction phase structure begin to act collectively (coherently), and they transmit the structure of its functions; will now represent elements of the Micro-level as a single system. Functions characterize the collective action of Micro-level elements are formed at the Macrolevel. They are called Order Parameters (OP) and act by self-organization dissipative structures. The elements of the Macro-level using the Control Parameters (CP) manage elements that are on the Mega-level.

The system is in equilibrium as long as using negative feedbacks can control the level of fluctuations within acceptable limits. But under the influence of entropy coming from the external environment as well as their own, internal, the system may lose equilibrium state and move to phase Formation. Stage of Formation characterizes the evolution of the system: transition to chaos, loss of a structure, change Attractors, Control Parameters and Order Parameters and the transition to another level of development.

Phase Chaos. The principle of non-linearity in Synergetics is the result of impacts on the amount of dissipative structures is not equal to the sum of their results. That is, as a result of entropy in the system increases, the internal fluctuations of dissipative structures micro-level, leading to output of the system a state stability, with even a minimal impact on the system can lead to catastrophic events and direct the system into chaos.

The principle of openness characterizes the ability of systems to exchange energy at the level of the hierarchical structure of the system and with the environment.

The principle of instability of the system indicates that due to the nonlinearity of processes in the system and its openness to external influences, the system has the ability to move from a state of homeostasis (a state of stable fluctuations around the Attractor) to a state that is characterized as chaos and reflects the unstable oscillation system. System instability leads her to the point of bifurcation, which determines the possible ways of further development of the system.

The development of dissipative structures in the transition through the bifurcation point is described by the principle of emergence. This principle describes the formation of a new dissipative structure due to the loss of the previous hierarchy structure, the emergence of order from chaos

The principle observation emphasizes the limitations and relativity of our perceptions about the system. From one side this limitation arises from the relative scale of observation, on the other - in relative observation time.

Using a synergistic approach to pedagogy based on the representation of the learning process of the evolution of dissipative structures, that is passing two stages: the stage of chaos, when arise situations of instability, uncertainty, alternative choice of the future path of development; stage order when the collective activity of structural elements contributes to its optimal functioning and selfdevelopment. So:

- openness of educational system provided by: 1) changing the values of the subjects learning and teaching content and instruments under the influence of external factors, 2) due to the impact of subjects learning and teaching and products of their activities on the environment;

- nonequilibrium of educational system caused entropy by coming to her in the form a certain amount of information and leads to fluctuations in the learning process. The level of entropy defined using positive and negative backward linkages. In the educational process the entropy increases abundance of information you want to learn students. Reduce the entropy can be optimized by 
training content, rational use of methodological tools, activation of attitudes of learning;

- non-linearity can be realized by multiple content, alternative forms and methods, differentiation and individualization of the learning process, all of which are field ways to develop the system;

- the ability to self-organize into coherent action expressed structural elements of the educational process aimed at achieving attractor-learning goals by reducing the entropy entering the system;

- complexity is in constructing a hierarchical educational system that reflects the features of the interaction elements, such as teachers, students and representatives of educational management.

\section{Synergetic Model of Formation of the Content of Stochastic Training of Future Economists}

Synergetic model of formation content of stochastic training of future economists are presented in Figure 1.

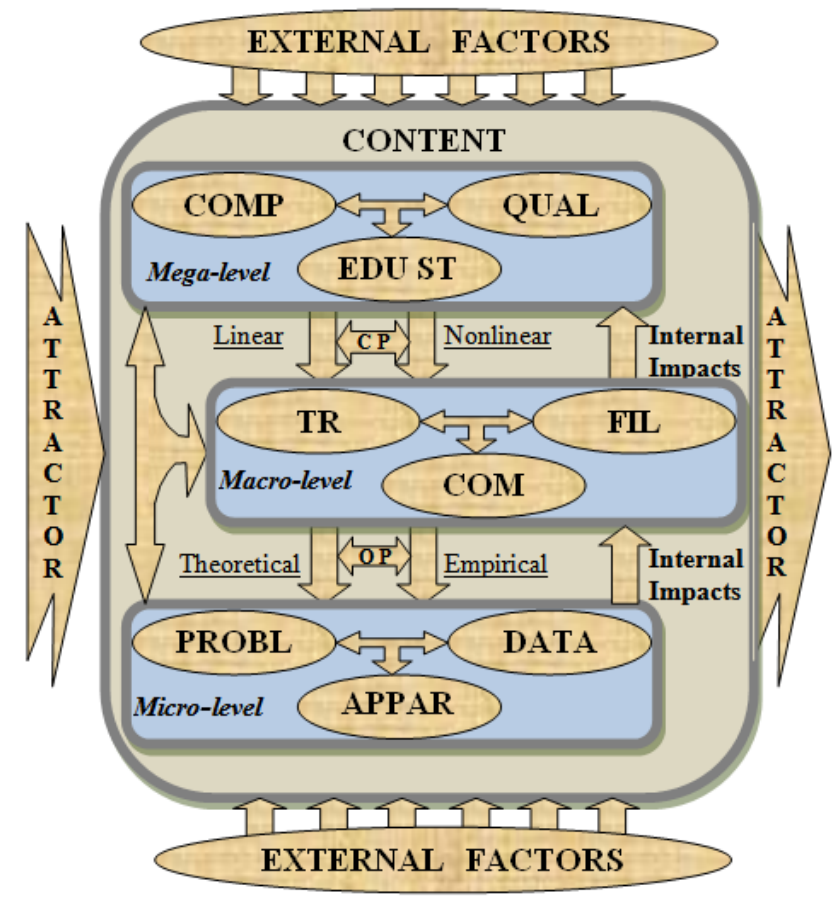

Figure 1. Synergetic model of stochastic training content

The construction of a synergetic system begins with a stage of Chaos. At this stage under the influence of Attractor, which is the formation of the content of Stochastics for economists, begins the interaction between the elements of the Mega- and Micro-level.

To construct the model let us present a Mega-level as a set of three groups of elements which are slowly changing under the influence of external and internal factors:

- Competencies (COMP) that characterize the individual's capacity to solve problems of defined range;

- Qualifications (QUAL) that determine the level requirements of employers regarding worker readiness to perform professional duties;

- Education Standards (EDU ST) that define the place of the stochastic training in the study of future economists.
Micro-level - is a level of high rate changes and the interaction of the following groups of elements:

- Problems (PROBL) related to the study of random phenomena and situations;

- Data (DATA) that are subject of the analysis;

- Apparatus (APPAR) that includes theoretical knowledge and technological tools necessary to solve the problem.

During the direct interaction between the elements belonging to the Micro- and Mega- levels formed Control Parameters (CP) that contribute to the emergence of Macro-level elements and direct their evolution in the direction of Attractor. In the investigated model Control Parameters define approaches to formation of the content of Stochastics: Linear (differentiated, integrative) or Nonlinear (synergistic).

Elements of the Macro-Level, determine the long-term development of the system - the content of stochastic training of future economists and divided into the following groups:

- Communication (COM) that reflects the logic of interaction between structural units of disciplines

- Filling (FIL) which is a list of topics that form the content of the discipline;

- Trajectory (TR) - a sequence of input concepts in the structure of the content.

Due to the interaction of Micro-level elements are formed Order Parameters (OP) of the system, defined as methods of calculating the probability of occurrence of a random phenomenon: Theoretical (T) and Empirical (E). Order parameters causing the phenomenon of selforganization on the content of stochastic training of future economists, the system creates a complex structure and proceeds to phase order. In order phase synergetic system closest to its attractor around which makes slight changes under the influence of internal and external factors.

\section{Practical Implementation Model}

Consider the possibility of practical application of the proposed model.

The Trajectory of the content discipline represented as a sequence of three content blocks: 1. Random Events; 2. Random Variables; 3. Random Processes and a list of related topics. Element of Macro-level Communication defined as the basic concept that enables create synergies content of each block. Filling represented as a set of basic concepts that characterize the Order Parameters, and methods of stochastic analysis of random phenomena, which are formed by the interaction of these parameters. In Table 1 shows the logical structure of the learning content Stochastics future economists.

\section{Acknowledgement}

The proposed system of formation of training the content of Stochastics to students of economic specialties of universities is synergetic because it:

- Difficult, as it has a hierarchical structure of a process;

- Dynamic, relative to trajectory content;

- Non-linear in the case of interconnection between the basic concepts and thus, capable of self-organization; 
Table 1. Logical Structure of Learning Content Stochastics

TRAJECTORY:

RANDOM EVENTS

\begin{tabular}{|c|c|c|}
\hline & \multicolumn{2}{|c|}{$\begin{array}{l}\text { TRAJECTORY: } \\
\text { RANDOM EVENTS }\end{array}$} \\
\hline $\begin{array}{l}\text { COMMUNI } \\
\text { CATION }\end{array}$ & \multicolumn{2}{|c|}{ The measure, which characterizes the possibility of events: $\operatorname{Mes}(A)=\frac{n(A)}{n(\Omega)}$} \\
\hline 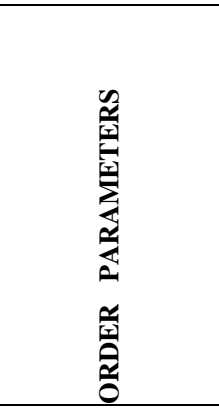 & $\begin{array}{l}\text { Theoretical: } \\
\qquad M e s(A) \equiv P(A)=\frac{n(A)}{n(\Omega)} \\
\text { - probability of random events } \\
A=\{\text { a random event that may occur as a result of theoretical } \\
\text { research }\} ; \\
\Omega=\{\text { sample space is a set of elementary consequences trials }\} ; \\
n(A)-\text { number of possible consequences trials that are contributing } \\
\text { to the event A; } \\
n(\Omega) \text { - total number of all possible elementary consequences of the } \\
\text { trials }\end{array}$ & 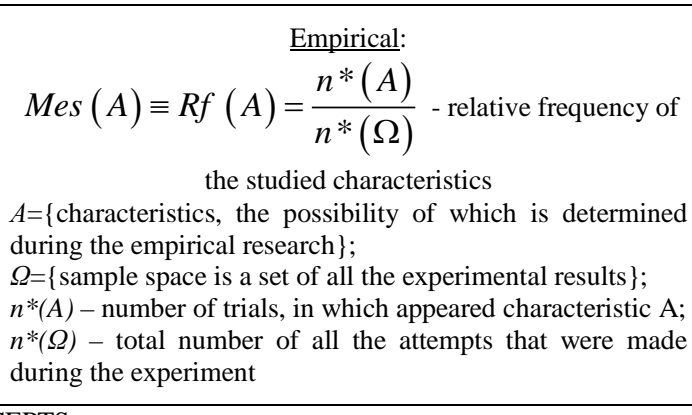 \\
\hline \multirow{7}{*}{ 䛼 } & \multicolumn{2}{|c|}{ BASIC CONCEPTS } \\
\hline & \multirow{2}{*}{\multicolumn{2}{|c|}{$\begin{array}{l}\text { Topic 1. Basic concepts of Probability and Statistics } \\
\text { STOCHASTIC ANALYSIS OF RANDOM EVENTS }\end{array}$}} \\
\hline & & \\
\hline & \multicolumn{2}{|c|}{ Topic 2. Elements of Combinatorics } \\
\hline & \multicolumn{2}{|l|}{ Topic 3. Addition and Multiplication Theorems of Probability } \\
\hline & \multicolumn{2}{|l|}{ Topic 4. Bernoulli Trials } \\
\hline & \multicolumn{2}{|c|}{$\begin{array}{c}\text { TRAJECTORY: } \\
\text { RANDOM VARIABLES }\end{array}$} \\
\hline $\begin{array}{l}\text { COMMUNI } \\
\text { CATION }\end{array}$ & \multicolumn{2}{|c|}{$\begin{array}{l}\text { Function that sets the ratio between the possible outcomes of stochastic experiment and unique numeric values that determine the } \\
\qquad \text { possibility of these results } Z=f(\text { Out; Mes ) }\end{array}$} \\
\hline 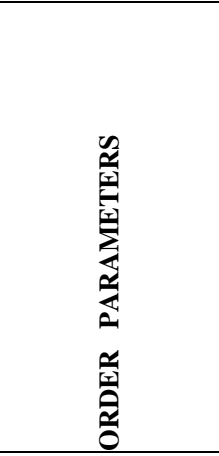 & 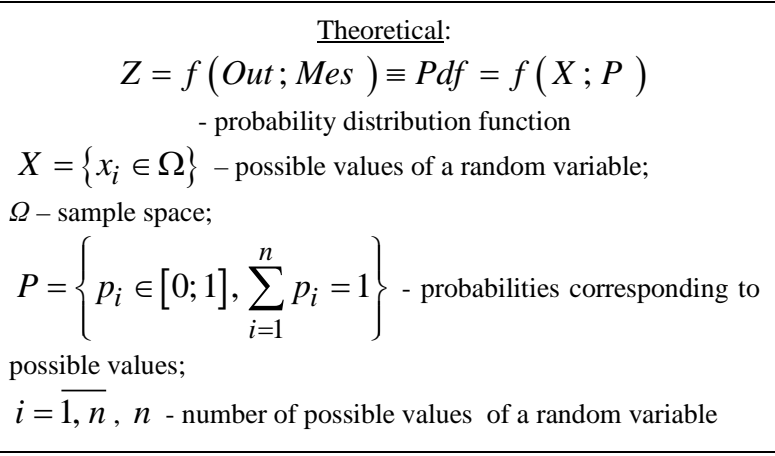 & 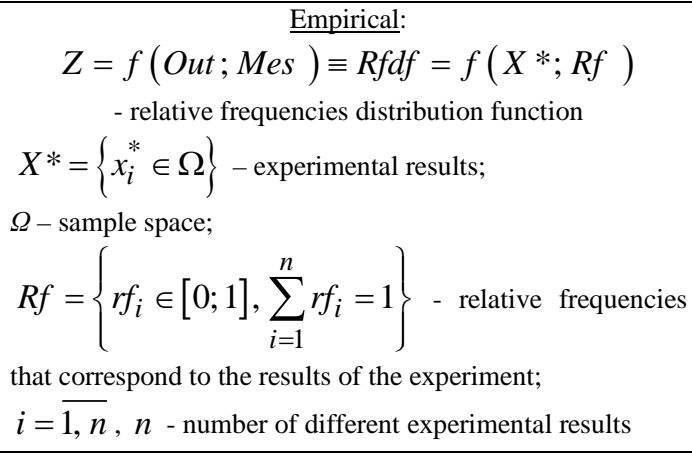 \\
\hline \multirow{12}{*}{ 岂 } & \multicolumn{2}{|c|}{ BASIC CONCEPTS } \\
\hline & \multicolumn{2}{|l|}{ Topic 6. Numerical Characteristics of Random Variables } \\
\hline & \multicolumn{2}{|l|}{ Topic 7. Multidimensional Random Variables } \\
\hline & \multicolumn{2}{|l|}{ Topic 8. Numerical Characteristics of Multidimensional Random Variables } \\
\hline & \multicolumn{2}{|l|}{ STOCHASTIC ANALYSIS OF RANDOM VARIABLES } \\
\hline & \multicolumn{2}{|l|}{ Topic 9. Classic Distribution of Random } \\
\hline & \multicolumn{2}{|l|}{ Topic 10. The Law of Large Numbers and the Central Limit Theorem } \\
\hline & \multicolumn{2}{|l|}{ Topic 11. Parameter Estimation } \\
\hline & \multicolumn{2}{|l|}{ Topic 12. Hypothesis Testing } \\
\hline & \multicolumn{2}{|l|}{ Topic 13. Regression Analysis } \\
\hline & \multicolumn{2}{|l|}{ Topic 14. Analysis of Variance (ANOVA) } \\
\hline & \multicolumn{2}{|c|}{$\begin{array}{c}\text { TRAJECTORY: } \\
\text { RANDOM PROCESSES } \\
\end{array}$} \\
\hline $\begin{array}{l}\text { COMMUNI } \\
\text { CATION }\end{array}$ & \multicolumn{2}{|c|}{$\begin{array}{l}\text { Way of representing a random process } \\
\qquad X(t)=f(C S ; \text { Re } a l)\end{array}$} \\
\hline \multirow{3}{*}{$\begin{array}{l}\text { ORDER } \\
\text { PARAMETERS }\end{array}$} & $\begin{array}{c}\qquad X(t)=\left\{\begin{array}{c}\text { Theoretical: } \\
\left\{C S\left(t_{i}\right), i=\overline{0, \infty}\right\}\end{array}\right. \\
\text { Cross section as a random variable } C S\left(\mathrm{t}_{0}\right) \text {, defined for any fixed } \\
\text { value of } t=t_{0}\end{array}$ & $\begin{array}{c}\text { Empirical: } \\
\qquad X(t)=\left\{\operatorname{Re} a l_{i}(t), i=\overline{0, \infty}\right\} \\
\text { Realization of a nonrandom function } \operatorname{Real}(t) \text {, which } \\
\text { becomes a random process as a result of trials }\end{array}$ \\
\hline & $X(t)$ & \\
\hline & \multicolumn{2}{|c|}{$\frac{t_{0}}{\text { BASIC CONCEPTS }}$} \\
\hline \multirow{3}{*}{ FILLING } & \multicolumn{2}{|l|}{ Topic 15. Random Processes } \\
\hline & STOCHASTIC ANALYSIS OF & RANDOM PROCESSES \\
\hline & & \\
\hline
\end{tabular}


- Opened and non-equilibrium due to internal and external influences that can alter the substantive content (eg, due to the important economic activities tasks as stochastic simulation of random processes, expert evaluation, qualitative analysis of random factors).

\section{References}

[1] Batanero, C. and Diaz, C., "Training school teachers to teach probability: reflections and challenges", Chilean Journal of Statistics, 3 (1). 3-13. Apr.2012.

[2] Daňhel, J., Duchačkova, E. and Radova, J., "Economic Theory Needs a New View of the Phenomenon of Randomness", Journal of Emerging Trends in Economics and Management Sciences (JETEMS), 4 (5). 460-466. 2013.

[3] “Global Risks 2014. Ninth Edition: Insight Report”, World Economic Forum. [Online].

Available:

http://www3.weforum.org/docs/WEF_GlobalRisks_Report_2014. pdf. [Accessed Jul. 2, 2014].

[4] Janson, N. B., "Non-linear dynamics of biological systems Contemporary Physics”, 2010. [Online].

Available:

http://homepages.lboro.ac.uk/ manbj/PAPERS/janson_paper_resu b2.pdf [Accessed Jut. 18, 2014].
[5] Laycraft, K., "Chaos, Complexity, and Creativity”, Mathematics, Music, Art, Architecture, Culture, Bridges, 2009. [Online].

Available: http://archive.bridgesmathart.org/2009/bridges2009355.pdf [Accessed Jul. 12, 2014].

[6] Liening, A., "Synergetics - Fundamental Attributes of the Theory of Self-Organization and Its Meaning for Economics”, Modern Economy, 5. 841-847. 2014.

[7] Prediger, S., "Do you want me to do it with probability or with my normal thinking? Horizontal and vertical views on the formation of stochastic conceptions”, International Electronic Journal of Mathematics Education, 3. 126-154. 2008.

[8] Rosser, J. B., “Aspects of dialectics and nonlinear dynamics”, Cambridge Journal of Economics, 24 (3). 311-324. May 2000.

[9] Arshinov, V.A., "Philosiphy of Education and Synergetics: how synergetics may cooperate in molding a new education model?” [Online].

Available: http://spkurdyumov.narod.ru/Arsh.htm [Accessed Sep. 21, 2013].

[10] Budanov, V.G., “Transdisciplinary Education, Technologies and principles of Synergetics. Synergetic paradigm”, 'Progresstradition” Moscow, 2000, 305.

[11] Byatets, I.V., "Reasons for the emerging and measuring uncertainties and risk in economics, Letters of the Udmurt University. Series: Economics and Law, 4. 14-18. 2011.

[12] Stepin, V.S., "Theoretical knowledge”. [Online]. Available: http://philosophy.ru/library/stepin/index.html [Accessed Nov. 16, 2013].

[13] Haken, H., Synergetics, Mir, Moscow, 1980, 406. 